\title{
Antitumor effect of TW-37, a BH3 mimetic in human oral cancer
}

\author{
Chi-Hyun Ahn ${ }^{1 \dagger}$, Won Woo Lee ${ }^{2 \dagger}$, Yun Chan Jung ${ }^{3}$, Ji-Ae Shin', Kyoung-Ok Hong', Sujung Choi ${ }^{1}$, Neeti Swarup', \\ Jihoon Kim ${ }^{1}$, Min-Hye Ahn', Minjung Jung ${ }^{1}$, Sung-Dae Cho ${ }^{1 *}$ (ID and Bohwan Jin ${ }^{2^{*}}$
}

\begin{abstract}
TW-37 is a small molecule B cell lymphoma-2 (Bcl-2) homology 3 mimetic with potential anticancer activities. However, the in vivo anti-cancer effect of TW-37 in human oral cancer has not been properly studied yet. Here, we attempted to confirm antitumor activity of TW37 in human oral cancer. TW-37 significantly inhibited cell proliferation and increased the number of dead cells in MC-3 and HSC-3 human oral cancer cell lines. TW-37 enhanced apoptosis of both cell lines evidenced by annexin V/propidium iodide double staining, sub- $\mathrm{G}_{1}$ population analysis and the detection of cleaved poly (ADP-ribose) polymerase and caspase-3. In addition, TW-37 markedly downregulated the expression of $\mathrm{BCl}-2$ protein, while not affecting $\mathrm{BCl}-\mathrm{xL}$ or myeloid cell leukemia-1. In vivo, TW-37 inhibited tumor growth in a nude mice xenograft model without any significant liver and kidney toxicities. Collectively, these data reveal that TW-37 may be a promising small molecule to inhibit human oral cancer.
\end{abstract}

Keywords: TW-37, Apoptosis, Bcl-2, Oral cancer

\section{Introduction}

With a development of patient screening tools and a research on pathways involved in tumorigenesis, anticancer drug research was developed by converting from chemotherapy inducing cytotoxic responses to target therapy that interferes specific molecules associated with tumorigenesis [1]. Induction of apoptosis by molecular target-based drugs plays a critical role in cancer treatment against various types of cancers [2-4]. The antiapoptotic Bcl-2 molecules including B-cell lymphoma 2 (Bcl-2) are key regulators of apoptosis by suppressing the activation of proapoptotic $\mathrm{Bcl}-2$ family [5] and these proteins were often over-expressed in many cancers [6, 7]. Recently, several studies showed that small molecules exhibited anticancer activity by targeting Bcl-2 family which is associated with intrinsic pathways of apoptosis $[8,9]$. Thus, the development of

\footnotetext{
* Correspondence: efiwdsc@snu.ac.kr; jnbhwan@cha.ac.kr

${ }^{\dagger}$ Chi-Hyun Ahn and Won Woo Lee contributed equally to this work.

${ }^{1}$ Department of Oral Pathology, School of Dentistry and Dental Research

Institute, Seoul National University, Seoul 03080, Republic of Korea

${ }^{2}$ Laboratory Animal Center, CHA University, CHA Biocomplex,

Sampyeong-dong, Seongnam 13488, Republic of Korea

Full list of author information is available at the end of the article
}

anti-apoptotic Bcl-2 inhibitors has important implications for cancer treatment and prevention.

TW-37 is a second-generation benzenesulphonyl derivative of gossypol isolated from cotton seeds and roots. It was recently demonstrated that TW-37 attenuated the activation of Bcl-2, Bcl-xL and myeloid cell leukemia-1 (Mcl-1) via directly binding to Bcl-2 homology 3 (BH3) binding groove with high affinity, resulting in the induction of apoptosis $[10,11]$. In the case reports of oral cancer patients, anti-apoptotic Bcl-2 family proteins were markedly increased in precancerous lesions suggesting that they can act as oncoproteins for oral carcinogenesis [12-14]. Previously, our group published that BH3 mimetics such as ABT-263 and ABT-737 exhibited apoptosis-inducing potential in oral cancer [15-17]. Recently, we also showed the in vitro anti-cancer effects of TW-37 in human oral cancer cell lines [18]. These suggest that small molecule inhibitors targeting $\mathrm{Bcl}-2$ family proteins can be a promising drug candidate against human oral cancer. To date, however, no study on the in vivo effect of TW-37 in oral cancer has been conducted.

In the present study, we sought to identify in vitro and in vivo anti-cancer activity of TW-37 in human oral cancer.

(c) The Author(s). 2019 Open Access This article is distributed under the terms of the Creative Commons Attribution 4.0 International License (http://creativecommons.org/licenses/by/4.0/), which permits unrestricted use, distribution, and 


\section{Methods}

\section{Cell culture and treatment}

The MC-3 mucoepidermoid carcinoma cell line was kindly provided by prof. Wu Junzheng (Forth Military Medical University, Xi'an, China) and HSC-3 oral squamous cell carcinoma cell line was given by Prof. Masanobu Shindoh from Hokkaido University (Hokkaido, Japan). Cells were cultured in Dulbecco's Modified Eagle Medium/F12 supplemented with $10 \%$ heat inactivated fetal bovine serum and antibiotics at $37{ }^{\circ} \mathrm{C}$ in a humidified atmosphere $5 \% \mathrm{CO}_{2}$. All experiments were performed when the cells reached approximately 50 60\% confluence. TW-37 (ApexBio, Houston, TX, USA) was dissolved in dimethyl sulfoxide (DMSO), aliquoted, and stored at $20^{\circ} \mathrm{C}$. Final concentration of DMSO did not exceed $0.1 \%$.

\section{Trypan blue exclusion assay}

The anti-proliferative effect of TW-37 was determined with trypan blue solution (Gibco, Paisley, UK). The number of viable cells, unstained with trypan blue (0.4\%) solution, was counted using a hemocytometer with a light microscope.

\section{Live/dead assay}

The cytotoxicity of TW-37 was determined using a Live/ Dead Viability/Cytotoxicity assay kit (Life Technologies, Grand Island, NY). The principle of this kit is that live cells are distinguished by the presence of ubiquitous intracellular esterase activity. Briefly, cells were stained with $2 \mu \mathrm{M}$ calcein-AM and $4 \mu \mathrm{M}$ ethidium homodimer-1 and incubated for $30 \mathrm{~min}$ at room temperature (RT) according to the manufacturer instructions. Cells were then observed using a fluorescence microscopy (Leica DMi8, Wetzlar, Germany).

\section{Annexin V/PI double staining}

Apoptosis was evaluated by double staining with annexin V-fluorescein isothiocyanate (FITC) and propidium iodide (PI), according manufacturer's instructions of annexin V apoptosis assay kit (BD Biosciences, Franklin Lakes, NJ, USA). The stained cells were analyzed in fluorescenceactivated cell sorting (FACS) caliber (Becton-Dickinson) and calculated with Flowjo software (Flowjo LLC, Ashland, OR, USA).

\section{Cell cycle analysis}

Cells were fixed with $70 \%$ ethanol overnight at $4{ }^{\circ} \mathrm{C}$. $20 \mu \mathrm{g} / \mathrm{mL}$ (final concentration) of RNase $\mathrm{A}$ and PI (P4170, Sigma-Aldrich) were added and then incubated for $15 \mathrm{~min}$ at $37^{\circ} \mathrm{C}$. DNA contents were detected using FACS caliber and the relative DNA content was and calculated with FlowJo software.

\section{Western blotting}

After treatment, the cells were harvested, rinsed with phosphate buffered saline (PBS), and then lysed with a lysis buffer on ice. The total protein concentration was measured using a DC Protein Assay Kit (BIO-RAD Laboratories, Madison, WI, USA). The same amount of protein was then loaded onto sodium dodecyl sulfate polyacrylamide gel electrophoresis and transferred onto an immunoblot polyvinylidene fluoride membranes. The membrane was blocked for $2 \mathrm{~h}$ in $5 \%$ skim milk in trisbuffered saline with Tween 20 and incubated with primary antibodies overnight at $4{ }^{\circ} \mathrm{C}$ and corresponding horseradish peroxidase-conjugated secondary antibodies. Antibodies against cleaved poly (ADP-ribose) polymerase (PARP), cleaved caspase-3, Bcl-xL and Mcl-1 were purchased from Cell Signaling Technology, Inc. (Charlottesville, VA, USA) and antibodies against Bcl-2 and $\beta$ actin were obtained from Santa Cruz Biotechnology, Inc. (Santa Cruz, CA, USA). Chemiluminescence were detected by SuperSignal West Pico Chemiluminescent Substrate (Santa Cruz Biotechnology Inc.) and were captured by X-ray film or ImageQuant LAS 500 (GE Healthcare Life Sciences, Piscataway, NJ, USA).

\section{Nude mouse model of human tumor}

Six-week-old Balb/c nu/nu male mice (NARA Biotech, Pyeongtaek, Korea) were caged in a facility with a 12-h light/dark cycle and allowed Teklad diet (2018s) and water ad libitum. All mice were handled according to Institutional Animal Care and Use Committee (IACUC) guidelines approved by CHA University (IACUC approval number: 190077). HSC-3 cells were subcutaneously injected into the flanks of the mice and the mice were then assigned randomly to two treatment groups (four mice per group). About 10 days after incubation, tumor-bearing mice were injected intraperitoneally with either vehicle control (PBS) or TW37 (15 mg/kg/day) for 21 days (5 days per week). Tumor volume and was monitored twice a week. Tumor volumes were measured along the two diameter axes with calipers and the tumor volumes were calculated using the equation volume $=\pi$ / $6 \times([\mathrm{D}+\mathrm{d}] / 2)^{3}$, where $\mathrm{D}$ and $\mathrm{d}$ are the larger and smaller diameters, respectively. At the termination of the experiment, mice were euthanized, tumors were retrieved to measure tumor weight.

\section{Histopathological findings}

Mouse organs (liver and kidneys) were fixed in $10 \%$ neutral buffered formalin. Tissue sections were cut to a thickness of $4 \mu \mathrm{m}$ and stained with hematoxylin (Mayer's, Klinipath, Benelux) and eosin (Eosin Y, Klinipath, Benelux). Histopathological changes were analyzed under a Nikon Eclipse E800 microscope. 

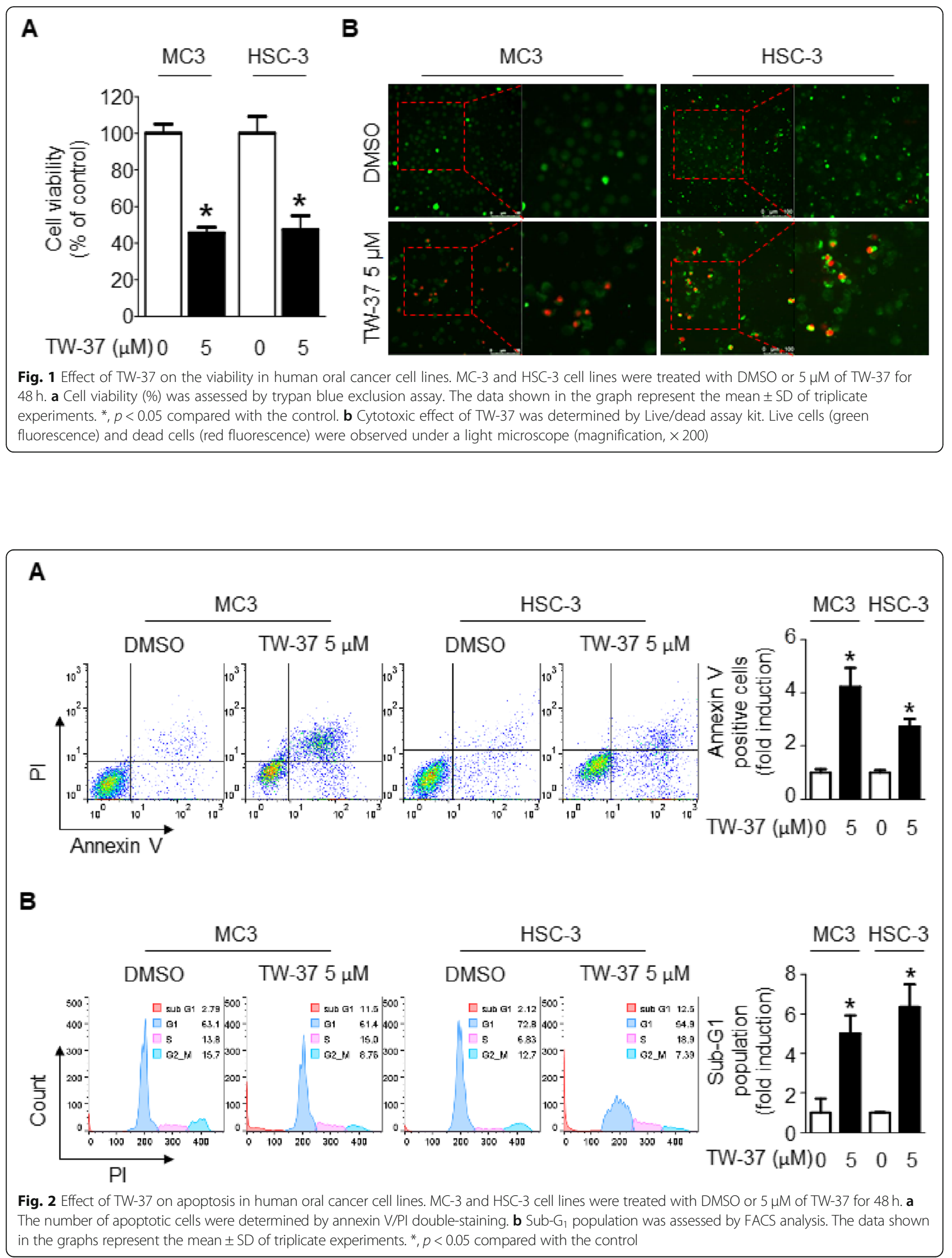


\section{Statistical analysis}

For the in vitro study, ANOVA followed by Tukey's post hoc test were used to determine the significance between the control and treatment groups. For the in vivo study, statistical evaluation was performed using the Mann-Whitney $U$ test in SPSS because our data were non-parametric. $p$ value of $<0.05$ was considered significant (*).

\section{Results}

Tw-37 inhibits cell growth and viability in MC-3 and HSC3 human oral cancer cell lines

To explore the anti-proliferative effects of TW-37, MC-3 and HSC-3 cell lines were treated with TW-37 $(5 \mu \mathrm{M})$ for $48 \mathrm{~h}$ and cell growth was evaluated by a trypan blue exclusion assay. Treatment with TW-37 significantly reduced cell proliferation by more than $50 \%$ compared with the control (Fig. 1a). Next, we performed a twocolor fluorescence assay, which detects esterase activity or cell permeability to confirm the cytotoxic effect of TW-37 in both cell lines. As shown in Fig. 1b, the number of red fluorescence-positive cells by EthD-1 was markedly increased. These results suggest that TW-37 may have anti-proliferative effect by inhibiting cell growth and inducing cell death in human oral cancer cell lines.

TW-37 increased the apoptotic cell population in human oral cancer cell lines

To date, many researches revealed that TW-37 can induce apoptotic response in various types of cancer cell lines [16-19]. Thus, we performed annexin V/PI staining and DAPI staining to evaluate the effect of TW-37 in MC-3 and HSC-3 cell lines. The results showed that the

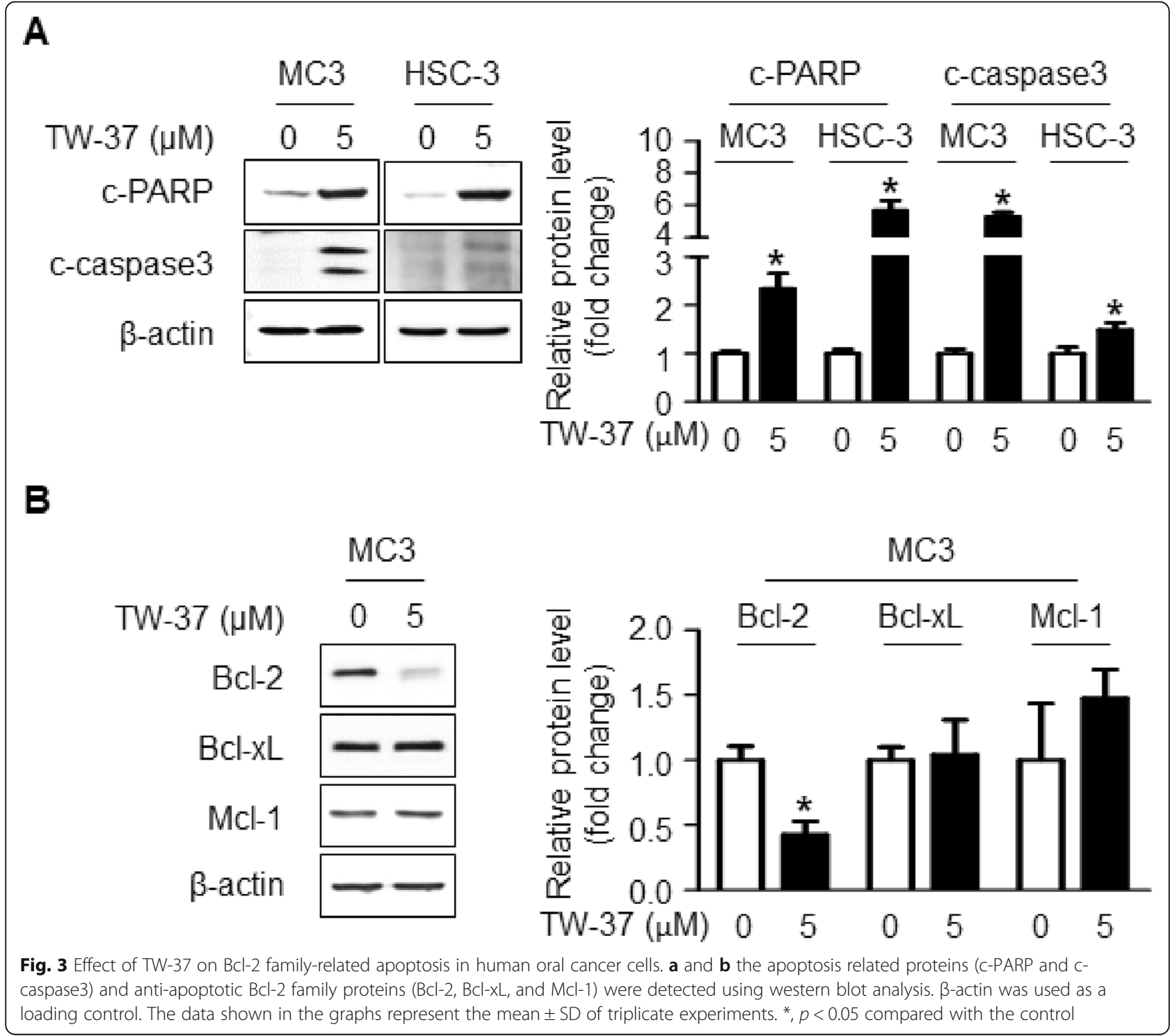


percentage of apoptotic cell population (annexin $\mathrm{V}$ FITC-positive) in TW-37- treated group $(25.38 \%$ for MC-3 cells and $37.00 \%$ for HSC-3 cells) dramatically increased compared with in control-treated group $(8.74 \%$ for MC-3 cells and $13.54 \%$ for HSC-3 cells) (Fig. 2a). We further performed cell cycle analysis to determine the sub- $G_{1}$ population. As shown in Fig. $2 b$, the appearance of sub- $G_{1}$ peak (apoptotic feature) was significantly induced by TW-37 (7.53\% for MC-3 cells and $13.70 \%$ for HSC-3 cells) compared with control $(0.64 \%$ for MC-3 cells and $2.15 \%$ for HSC-3 cells). These results suggest that TW-37 can induce morphological changes of apoptotic body and fraction of DNA associated with apoptosis in human oral cancer cells.

TW-37 induced the apoptosis by downregulating Bcl-2 protein in human oral cancer cells

To ascertain TW-37-mediated apoptosis in human oral cancer cell lines, we did western blotting using antibodies against cleaved caspase3 and cleaved PARP, which are known as apoptosis-related protein markers. As shown in Fig. 3a, TW-37 treatment effectively induced apoptotic cell death, as evidenced by the cleavages of caspase 3 and PARP. Because TW-37 is one of BH-3 mimetics that are able to target anti-apoptotic Bcl-2 family proteins, we investigated whether TW-37 affects those proteins such as Bcl-2, Bcl-xL, and $\mathrm{Mcl}-1$. As shown in Fig. 3b, Bcl-2 expression was significantly reduced by TW-37 while not affecting Bcl-xL and Mcl-1 protein. These results suggest that TW-37-induced apoptosis may be related with the downregulation of Bcl-2 protein.
TW-37 suppresses tumor growth in a tumor xenograft model without any toxicity

To evaluate the efficacy of in vivo antitumor activity of TW-37, we used a xenograft mice model by subcutaneously injection of HSC-3 cells into the flank of athymic nude mice. As shown in Fig. 4a and b, TW-37 treatment significantly decreased tumor volume on day 16 after the treatment. Consistent with this, the average of tumor weight was reduced at a very slight trend toward significance (Fig. 4c). Next, to investigate the effects of TW-37 on in vivo biocompatibility, we measured the body and organs (liver and kidneys) weights. TW-37 treatment did not affect significant changes of body and organs weight (Fig. 5). In addition, histopathologic evaluation of liver and kidney did not show any pathological differences between the control- and TW37-treated mice (Fig. 6). These results suggest that TW-37 administration suppresses tumor growth in our mouse xenograft model of human oral tumor without causing histopathological toxicity.

\section{Discussion}

Apoptosis is the most important physiological cell death and is tightly regulated by pro- and antiapoptotic cascades during development and aging. Homeostatic state between apoptosis and cell division is essential for maintaining cell populations in normal tissues. Thus, the dysregulation of apoptosis can cause many human diseases including cancer $[19,20]$. A number of small molecule inhibitors were previously designed to induce apoptosis against cancers by targeting anti-apoptotic Bcl-2 proteins characterized into groups based on their structure and function [21]. For instance, venetoclax
A

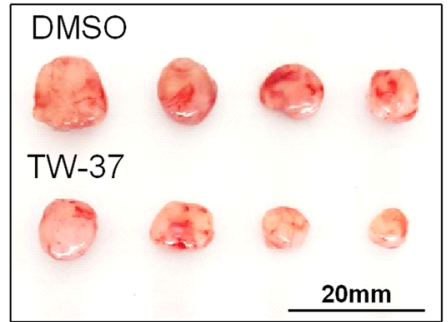

B

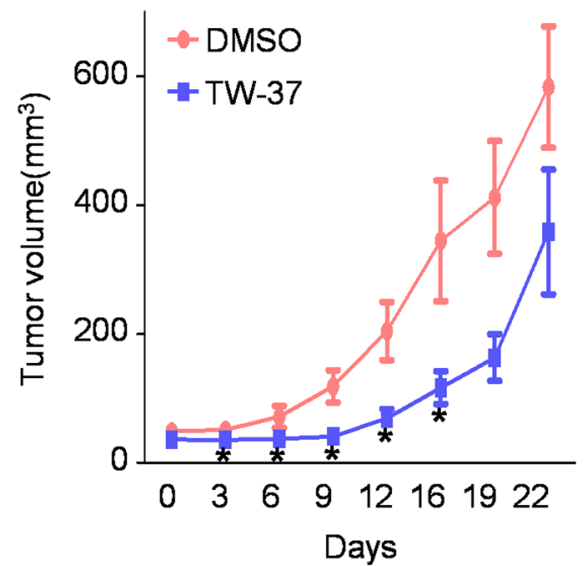

C

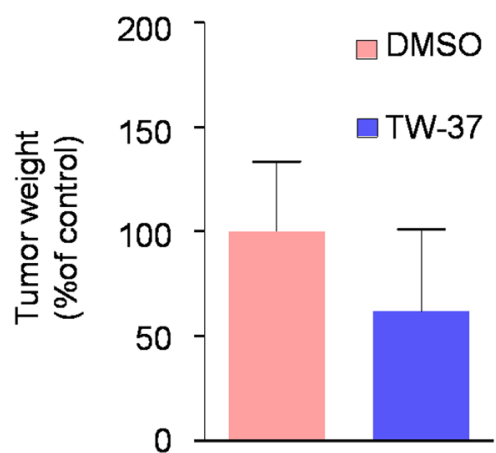

Fig. 4 Effect of TW-37 on tumor growth in a xenograft mice model. Balb/c nude baring HSC-3 cells were treated with vehicle control (PBS) or TW-37 (15 mg/kg/day) for 21 days ( $n=4 /$ group). a The photograph of tumor tissues. Tumor volume (b) and tumor weight (c) were measured. The values are presented as mean \pm SEM of 4 mice per group. ${ }^{*}, p<0.05$ compared with the control 


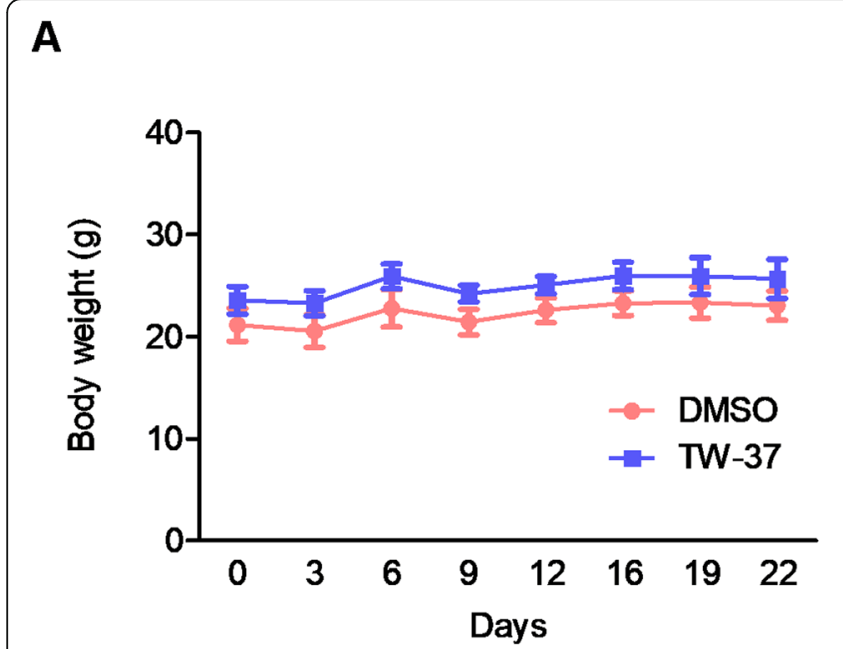

B

Fig. 5 Effect of TW-37 on body and organs weight. Body weight (a) and weights of liver and kidney (b) were measured after sacrifice. Each graph represents mean \pm SEM of 4 mice per group

(ABT-199/GDC-0199) is typical Bcl-2 inhibitor that plays a role as $\mathrm{BH} 3$ mimic for the treatment of Bcl-2dependent hematological cancers [22]. Lin et al. [23] also reported that ABT-263 induced cell cycle arrest, apoptosis and autophagy in human esophageal cancer cells.

In 2006, TW-37 was developed as a small molecule inhibitor of Bcl-2, Bcl-XL, and Mcl-1 and was shown to have anti-cancer activity in lymphoma cells [24]. Several researches showed that TW-37 stimulated apoptotic cell death and changed cytotoxicity towards the drugsensitive and resistance in nasopharyngeal carcinoma, colorectal cancer, ovarian cancer, and neuroblastoma [25-28]. In this study, we investigated the anti-cancer activity of TW-37 in MC-3 and HSC-3 human oral cancer cell lines. Consistent with the discovery of others, TW-37 significantly exhibited anti-cancer activity in human oral cancer cells via the induction of apoptosis. In addition, we found that TW-37 specifically affected $\mathrm{Bcl}-2$ proteins suggesting that $\mathrm{Bcl}-2$ is a major molecule target for TW-37-induced apoptosis as expected. In contrast, our group recently published that lower concentration $(1.25 \mu \mathrm{M})$ of TW-37 did not inhibit cell growth and

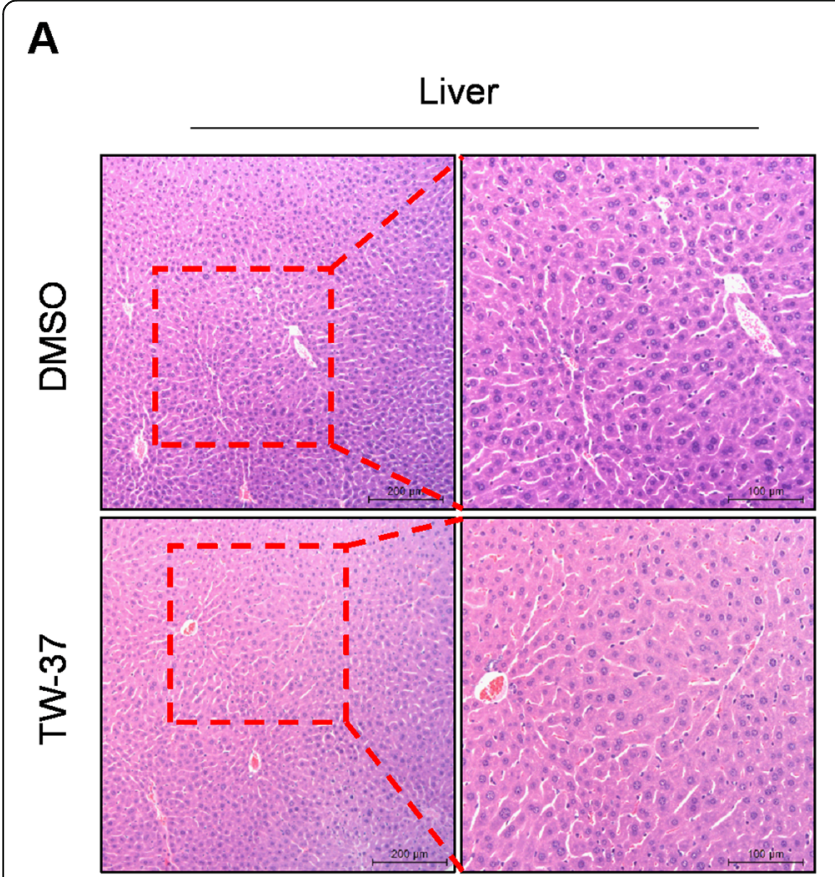

B

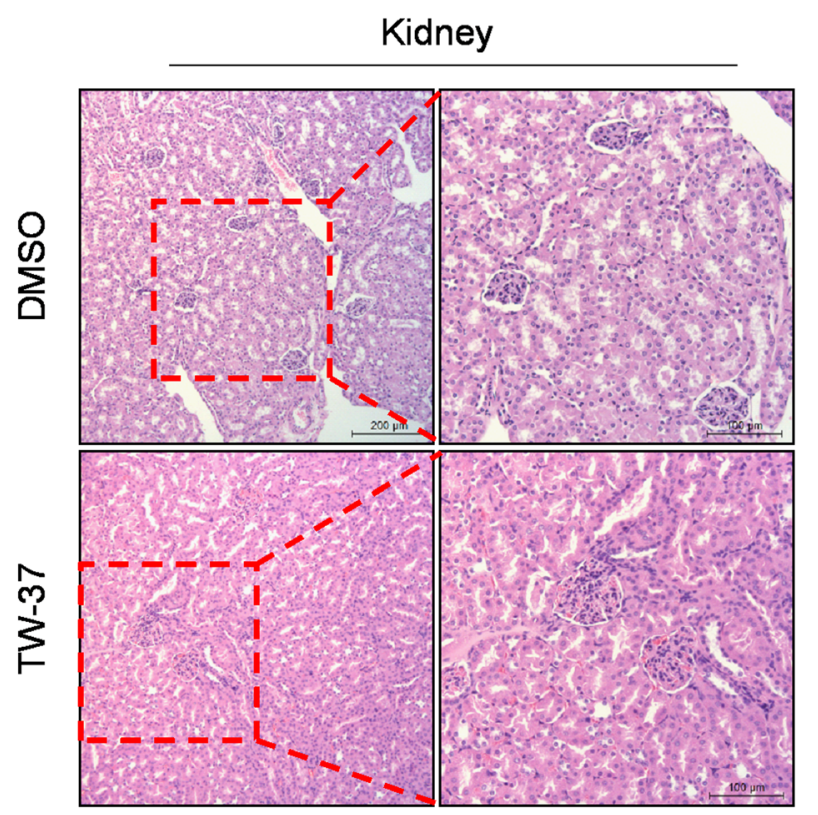

Fig. 6 Histopathological findings of liver (a) and kidney (b). (magnification, $\times 100$ ) 
induce apoptosis in $\mathrm{MC}-3$ cells [18]. It means that the findings of the current study do not support our previous research. A possible explanation for this might be that only higher concentration of TW-37 may be associated with Bcl-2 protein during its apoptotic activity in MC-3 cells. However, future investigations might explain why only higher concentration of TW-37 may act as a Bcl-2 inhibitor.

Several reports have shown that TW-37 treatment significantly inhibited tumor growth in vivo without any toxicity or any loss of body weight [25, 29]. However, there have been no studies using experimental animals for human oral cancer. In the present study, we found that TW-37 also suppressed tumor growth without any body weight loss and any histopathologic changes of both liver and kidney tissues (Figs. 4, 5 and 6). These data broadly support the work of other studies. However, one unanticipated finding was that it was only significantly effective until the day 16 of TW-37 material treatment and its antitumor activity was not significant at the time of sacrifice (Fig. 4b). It seems possible that these results may be due to the acquisition of drug resistance to TW-37 in MC-3 cells. However, we still need to determine how MC3 cells acquire drug tolerance in the early time. Innate or acquired resistance to chemotherapy is a major cause of treatment failure in cancer patients. Despite $\mathrm{BH} 3$ mimetics targeting members of Bcl-2 family have received much attention for the recent success of cancer treatments, particularly hematological malignancies, single drug BH3 mimetic therapy also has limited effectiveness [30, 31]. Actually, there are such previous studies showing that $\mathrm{BH} 3$ mimetics had drug resistances by compensatory activity of Mcl-1 for the inhibition of Bcl-2/Bcl-xL and Mcl-1 activation sensitized cancer cells to BH3 mimetics [32-35]. These suggest that the combinational therapeutic strategy could directly activate the cell death mechanism to overcome its limitation. Thus, it is worthwhile to clarify it in future studies although combination strategy with TW-37 remains unclear.

\section{Conclusions}

The study presented here showed the anti-cancer effects of TW37 in human oral cancer cell line and nude mice tumor xenograft model. Our findings provide a strong possibility of TW-37 as a potential antitumor agent for oral cancer despite several important questions still need to be explained.

\section{Abbreviations}

BCl-2: B cell lymphoma-2; BH3: BCl-2 homology 3; Mcl-1: Myeloid cell leukemia-1; PARP: Poly (ADP-ribose) polymerase

\section{Acknowledgements}

This work was supported by the Basic Science Research Program through the National Research Foundation of Korea (NRF) funded by the Ministry of Science ICT \& Future Planning [2019R1A2C1085896].

\section{Authors' contributions}

WWL and C-HA designed the study, performed experiments, and drafted the manuscript; $\mathrm{KOH}$ and J-AS contributed to manuscript preparation, study designing, and statistical analysis; YCJ, SJC, NS, JHK, M-HA, and MJJ contributed to data acquisition; S-DC and BWJ supervised the project and contributed to manuscript review and editing. All authors approved the final version of the manuscript.

\section{Funding}

This research received no external funding

\section{Availability of data and materials}

The datasets used and/or analyzed in this study are available from the corresponding author on reasonable request.

\section{Competing interests}

The authors declare that they have no competing interests.

\section{Author details}

${ }^{1}$ Department of Oral Pathology, School of Dentistry and Dental Research Institute, Seoul National University, Seoul 03080, Republic of Korea. 2Laboratory Animal Center, CHA University, CHA Biocomplex,

Sampyeong-dong, Seongnam 13488, Republic of Korea. ${ }^{3}$ Chaon, 301-3, 240,

Pangyoyeok-ro, Bundang-gu, Seongnam 13493, Republic of Korea.

Received: 3 October 2019 Accepted: 19 November 2019

Published online: 04 December 2019

\section{References}

1. Hoelder S, Clarke PA, Workman P. Discovery of small molecule Cancer drugs: successes, Challenges and Opportunities. Mol Oncol. 2012;6(2): 155-76.

2. Hengartner MO. The biochemistry of apoptosis. Nature. 2000;407(6805): 770-6.

3. Lucki NC, Villa GR, Vergani N, Bollong MJ, Beyer BA, Lee JW, et al. A cell type-selective apoptosis-inducing small molecule for the treatment of brain Cancer. Proc Natl Acad Sci U S A. 2019;116(13):6435-40.

4. Yang S, Mao Y, Zhang H, Xu Y, An J, Huang Z. The chemical biology of apoptosis: revisited after 17 years. Eur J Med Chem. 2019;177:63-75.

5. Tsujimoto Y. Role of $\mathrm{BCl}-2$ family proteins in apoptosis: Apoptosomes or mitochondria? Genes Cells. 1998;3(11):697-707.

6. Buolamwini JK. Novel anticancer drug discovery. Curr Opin Chem Biol. 1999; 3(4):500-9.

7. Shin JA, Jung JY, Ryu MH, Safe S, Cho SD. Mithramycin a inhibits myeloid cell Leukemia-1 to induce apoptosis in Oral squamous cell carcinomas and tumor Xenograft through activation of Bax and Oligomerization. Mol Pharmacol. 2013;83(1):33-41.

8. Mongre RK, Mishra CB, Prakash A, Jung S, Lee BS, Kumari S, et al. Novel Carbazole-Piperazine Hybrid Small Molecule Induces Apoptosis by Targeting $\mathrm{BCl}-2$ and Inhibits Tumor Progression in Lung Adenocarcinoma in Vitro and Xenograft Mice Model. Cancers (Basel). 2019;11(9):E1245.

9. Belmar J, Fesik SW. Small molecule Mcl-1 inhibitors for the treatment of Cancer. Pharmacol Ther. 2015;145:76-84.

10. Mohammad RM, Goustin AS, Aboukameel A, Chen B, Banerjee S, Wang G, et al. Preclinical studies of Tw-37, a new Nonpeptidic small-molecule inhibitor of $\mathrm{BCl}-2$, in diffuse large cell lymphoma Xenograft model reveal drug action on both BCl-2 and Mcl-1. Clin Cancer Res. 2007;13(7):2226-35.

11. Wang G, Nikolovska-Coleska Z, Yang CY, Wang R, Tang G, Guo J, et al. Structure-based Design of Potent Small-Molecule Inhibitors of antiapoptotic Bcl-2 proteins. J Med Chem. 2006;49(21):6139-42.

12. Juneja S, Chaitanya NB, Agarwal M. Immunohistochemical expression of BCl2 in Oral epithelial dysplasia and Oral squamous cell carcinoma. Indian J Cancer. 2015;52(4):505-10.

13. Sulkowska M, Famulski W, Sulkowski S, Reszec J, Koda M, Baltaziak M, et al. Correlation between $\mathrm{BCl}-2$ protein expression and some Clinicopathological features of Oral squamous cell carcinoma. Pol J Pathol. 2003;54(1):49-52.

14. Zhang K, Jiao K, Xing Z, Zhang L, Yang J, Xie X, et al. Bcl-Xl overexpression and its association with the Progress of tongue carcinoma. Int J Clin Exp Pathol. 2014;7(11):7360-77. 
15. Yang $\mathbb{H}$, Jung JY, Kim SH, Yoo ES, Cho NP, Lee H, et al. Abt-263 exhibits apoptosis-inducing potential in Oral Cancer cells by targeting C/Ebphomologous protein. Cell Oncol (Dordr). 2019;42(3):357-68.

16. Kim LH, Shin JA, Jang B, Yang $I H$, Won DH, Jeong JH, et al. Sorafenib potentiates Abt-737-induced apoptosis in human Oral Cancer cells. Arch Oral Biol. 2017;73:1-6.

17. Shin JA, Kim LH, Lee SJ, Jeong JH, Jung JY, Lee HN, et al. Targeting Erk1/2Bim signaling cascades by Bh3-mimetic Abt-737 as an alternative therapeutic strategy for Oral Cancer. Oncotarget. 2015;6(34):35667-83.

18. Yang $\mathrm{H}$, Ahn $\mathrm{CH}$, Cho NP, Jin B, Lee $W$, Jung $\mathrm{YC}$, et al. Heme Oxygenase-1 Is a Key Molecule Underlying Differential Response of Tw37-Induced Apoptosis in Human Mucoepidermoid Carcinoma Cells. Molecules. Molecules. 2019;24(9):1700.

19. Gross A, McDonnell JM, Korsmeyer SJ. BCl-2 family members and the mitochondria in apoptosis. Genes Dev. 1999;13(15):1899-911.

20. Obulesu M, Lakshmi MJ. Apoptosis in Alzheimer's disease: An understanding of the physiology, Pathology and Therapeutic Avenues. Neurochem Res. 2014;39(12):2301-12.

21. Wen $M$, Deng $Z K$, Jiang $S L$, Guan $Y D$, Wu HZ, Wang $X L$, et al. Identification of a novel Bcl-2 inhibitor by ligand-based screening and investigation of its anti-Cancer effect on human breast Cancer cells. Front Pharmacol. 2019:10:391

22. Souers AJ, Leverson JD, Boghaert ER, Ackler SL, Catron ND, Chen J, et al. Abt-199, a potent and selective Bcl-2 inhibitor, achieves antitumor activity while sparing platelets. Nat Med. 2013;19(2):202-8.

23. Lin QH, Que FC, Gu CP, Zhong DS, Zhou D, Kong Y, et al. Abt-263 induces G1/G0-phase arrest, apoptosis and autophagy in human esophageal Cancer cells in vitro. Acta Pharmacol Sin. 2017;38(12):1632-41.

24. Al-Katib AM, Sun Y, Goustin AS, Azmi AS, Chen B, Aboukameel A, et al. Sm of BCl-2 Tw-37 is active across a Spectrum of B-cell tumors irrespective of their proliferative and differentiation status. J Hematol Oncol. 2009;2:8.

25. Klenke S, Akdeli N, Stelmach P, Heukamp L, Schulte JH, Bachmann HS. The small molecule Bcl-2/Mcl-1 inhibitor Tw-37 shows single-agent cytotoxicity in neuroblastoma cell lines. BMC Cancer. 2019;19(1):243.

26. Lei $S$, Ding $Y, F u, Y, W u S$, Xie $X$, Wang $C$, et al. The preclinical analysis of Tw-37 as a potential anti-colorectal Cancer cell agent. PLoS One. 2017;12(10):e0184501.

27. Lu Y, Huang H, Yang $H$, Chen D, Wu S, Jiang Z, et al. Small Molecule Inhibitor Tw-37 Is Tolerable and Synergistic with Chemotherapy in Nasopharyngeal Carcinoma. Cell cycle (Georgetown, Tex). 2017;16(14): 1376-83.

28. Wang H, Zhang Z, Wei X, Dai R. Small-molecule inhibitor of Bcl-2 (Tw-37) suppresses growth and enhances Cisplatin-induced apoptosis in ovarian Cancer cells. J Ovar Res. 2015;8:3-3.

29. Wang Z, Azmi AS, Ahmad A, Banerjee S, Wang S, Sarkar FH, et al. Tw-37, a small-molecule inhibitor of Bcl-2, inhibits cell growth and induces apoptosis in pancreatic Cancer: involvement of Notch-1 signaling pathway. Cancer Res. 2009;69(7):2757-65.

30. Mukherjee N, Strosnider A, Vagher B, Lambert KA, Slaven S, Robinson WA, et al. Bh3 Mimetics induce apoptosis independent of Drp-1 in melanoma. Cell Death Dis. 2018;9(9):907.

31. Labi V, Grespi F, Baumgartner F, Villunger A. Targeting the Bcl-2-regulated apoptosis pathway by Bh3 Mimetics: a breakthrough in anticancer therapy? Cell Death Differ. 2008;15(6):977-87.

32. Konopleva M, Contractor R, Tsao T, Samudio I, Ruvolo PP, Kitada S, et al. Mechanisms of apoptosis sensitivity and resistance to the Bh3 mimetic Abt737 in acute myeloid leukemia. Cancer Cell. 2006;10(5):375-88.

33. Mazumder S, Choudhary GS, Al-Harbi S, Almasan A. MCl-1 phosphorylation defines Abt-737 resistance that can be overcome by increased Noxa expression in leukemic B cells. Cancer Res. 2012;72(12):3069-79.

34. Peddaboina C, Jupiter D, Fletcher S, Yap JL, Rai A, Tobin RP, et al. The Downregulation of Mcl-1 via Usp9x inhibition sensitizes solid tumors to BClxl inhibition. BMC Cancer. 2012;12:541.

35. Abid M, Sonawane YA, Contreras JI, Rana S, Natarajan A. Recent advances in Cancer drug development: targeting induced myeloid cell Leukemia-1 (Mcl-1) differentiation protein. Curr Med Chem. 2017;24(40): 4488-514.

\section{Publisher's Note}

Springer Nature remains neutral with regard to jurisdictional claims in published maps and institutional affiliations.

\section{Ready to submit your research? Choose BMC and benefit from}

- fast, convenient online submission

- thorough peer review by experienced researchers in your field

- rapid publication on acceptance

- support for research data, including large and complex data types

- gold Open Access which fosters wider collaboration and increased citations

- maximum visibility for your research: over $100 \mathrm{M}$ website views per year

At BMC, research is always in progress.

Learn more biomedcentral.com/submissions 